\title{
Poemas a Piraye, de Nazım Hikmet
}

\author{
Marco Syrayama de Pinto e John Milton
}

Nazım Hikmet é provavelmente o poeta turco mais conhecido do século XX. Seus poemas já foram traduzidos para várias línguas.

Embora Hikmet tenha se unido a Atatürk na Guerra da Independência da Turquia (1919-22) trabalhando como professor - profissão-chave para espalhar o nacionalismo turco-, ele já contestava a versão oficial que negou (e ainda nega) os massacres na Armênia em 1915, quando a Turquia era aliada da Alemanha.

Estudou sociologia e economia na Universidade de Moscou de 1921 a 1928 e entrou para o Partido Comunista da Turquia na década de 1920. Em 1928, depois de voltar à Turquia sem visto, escreveu artigos em jornais, roteiros de filmes e peças de teatro. Por causa de seu retorno ilegal, foi encarcerado. Foi solto em 1935 para ser sentenciado de novo, nesse caso por um tribunal militar, em 1938, por atividades que haviam levado jovens soldados a se revoltarem mais especificamente porque seu poema "O Épico de Sheik Bedreddin" estava sendo lido por jovens praças no Exército. Como resultado de processos internacionais, foi solto de novo em 1950.

Após perder a cidadania turca, morou na União Soviética e em outros países socialistas, finalmente tornando-se cidadão polonês em honra a seu antepassado que havia lutado contra os russos. No exílio viajou bastante, tornando-se membro do Conselho Mundial da Paz, dividindo plataformas com outros membros célebres 
como Sartre, Picasso, Neruda e Aragon. Seus poemas foram encenados por artistas famosos como Pete Seeger e Paul Robeson.

Casou-se três vezes. A seqüência de poemas líricos aqui apresentada foi escrita para sua primeira mulher, Piraye, na prisão. Logo depois de ser solto, em 1950, Hikmet e Piraye divorciaram-se.

Sua obra deixou de ser censurada na Turquia em 1964, e hoje seus livros e versões musicadas de sua obra podem ser encontrados em qualquer loja.

\section{Comentários sobre a tradução}

Todos os poemas foram traduzidos a partir do texto na língua original, o turco, a fim de que as idéias presentes nos originais não ficassem comprometidas por possíveis erros, distrações ou mesmo divergências presentes nas traduções para o inglês. Destas, tínhamos em mãos a antologia Beyond the Walls: Selected Poems, em tradução de Ruth Christie, Richard McKane e Talât Sait Halman (Anvil, 2003).

As traduções inglesas somente foram consultadas depois que as traduções para o português já tinham sido realizadas; tal consulta teve o intuito de cotejar as idéias, conferir se coincidiam ou divergiam e, neste caso, tentar entender por quê.

Não resta dúvida que é incomparavelmente melhor utilizarse do original, caso se tenha conhecimento para tal, numa tradução, e não fazê-la através de uma outra. Encontramos omissões em não poucos poemas vertidos ao inglês, como no caso do "Yirminci Asra Dair" ("Sobre o Século XX"): o final, em que Hikmet se dirige à sua amada - Hatçe ou Hatçem, "minha Hatçe" - foi totalmente omitido (esse poema se encontra em uma outra edição que a mencionada acima, a saber, Poems of Nazım Hikmet, traduzido por Randy Blasing e Mutlu Konuk, p. 94). Um outro problema, nesse caso um erro de tradução, é encontrado no poema "Yaşamaya Dair" ("Sobre o Vi- 
ver"). Em um dos versos desse poema a sentença "biz yine de güleceğiz anlatılan Bektaşi fıkrasına" é vertida ao inglês como "we can still laugh at Nasreddin hoca jokes" (Beyond the Walls, p. 166); traduzimos como "ainda riremos das piadas de Bektaşi", e acrescentamos uma nota de rodapé a fim de informar o leitor sobre esse personagem afim à cultura turca.

Procuramos, também, manter a formatação fiel ao original.

Quanto à dificuldade da tradução, podemos dizer que foi de nível fácil a médio, dependendo do poema. Contudo, na maioria dos casos foi fácil, visto que o poeta, dadas suas convicções socialistas, quase sempre se utilizava de um linguajar simples e acessível ao leitor médio da língua turca, esquivando-se, provavelmente de maneira consciente, de expressões obscuras de origem árabo-persa, $\mathrm{e}$ preferindo palavras mais coloquiais, usadas no cotidiano pelo povo turco, e que tinham raízes turcas.

Por fim, nos valemos, sobretudo, da inestimável ajuda da informante nativa Yasemin Gügüumcü, que nos regalou com sugestões e correções.

A seleção a seguir é uma amostra dos poemas que sairão na coletânea Poetas do Mundo: Nazım Hikmet (Universidade de Brasília) que deve ser publicada no decorrer de 2008. 


\section{Cartas a Piraye, de Nazım Hikmet: Poemas das horas 21-22}

Como é bom lembrar de você

Como é bom lembrar de você:

em meio a notícias de morte e vitória

na prisão,

passando dos quarenta anos de idade...

Como é bom lembrar de você:

na sua mão esquecida sobre um tecido azul,

e nos seus cabelos,

há a maciez serena do meu querido solo de Istambul...

É como uma segunda pessoa dentro de mim, a felicidade de amá-la...

O cheiro da folha do gerânio que fica na ponta dos dedos, uma calma ensolarada,

e o convite da carne:

dividida com linhas rubras, uma cálida, e profunda escuridão...

Como é bom lembrar de você, escrever sobre você, e deitar-me na prisão e pensar em você, a palavra que você disse em tal dia e em tal lugar não tanto ela em si, como o seu mundo de expressão... 
Como é bom lembrar de você.

Devo talhar alguma coisa de madeira para você de novo:

uma gaveta,

um anel,

e devo tecer uns três metros de seda fina,

E, imediatamente,

saltando do meu lugar

agarrando-me às trancas de minha janela

para o azul branquicento da liberdade

devo gritar o que escrevi para você...

Como é bom lembrar de você:

em meio a notícias de morte e vitória

na prisão,

passando dos quarenta anos de idade... 


\section{Piraye İçin Yazılmış : Saat 21-22 Şiirleri}

Ne güzel şey hatırlamak seni:

ölüm ve zafer haberleri içinden,

hapiste

ve yaşım kırkı geçmiş iken...

Ne güzel şey hatırlamak seni:

bir mavi kumaşın üstünde unutulmuş olan elin

ve saçlarında

vakur yumuşaklığı canımın içi İstanbul toprağının...

İçimde ikinci bir insan gibidir

seni sevmek saadeti...

Parmakların ucunda kalan kokusu sardunya yaprağının, güneşli bir rahatlık

ve etin daveti:

kıpkızıl çizgilerle bölünmüş

sicak

koyu bir karanlık...

Ne güzel şey hatırlamak seni,

yazmak sana dair,

hapiste sırtüstü yatıp seni düşünmek:

filânca gün, falanca yerde söylediğin söz,

kendisi değil

edasındaki dünya...

Ne güzel şey hatırlamak seni.

Sana tahtadan bir şeyler oymalıyım yine: 


\section{bir çekmece}

bir yüzük,

ve üç metre kadar ince ipekli dokumalıyım.

Ve hemen

firlayarak yerimden

penceremde demirlere yapışarak

hürriyetin sütbeyaz maviliğine

sana yazdıklarımı bağıra bağıra okumalıyım...

Ne güzel şey hatırlamak seni:

ölüm ve zafer haberleri içinden,

hapiste

ve yaşım kırkı geçmiş iken... 


\section{0 de setembro de 1945}

Nesta hora tardia

de uma noite de outono

estou repleto de suas palavras;

palavras que são eternas como o tempo e a matéria,

nuas como o olho,

pesadas como a mão,

e brilhantes como as estrelas.

Suas palavras chegaram a mim,

de seu coração, de sua cabeça e de sua carne.

As suas palavras a trouxeram,

eram: mãe,

eram: mulher

e companheira...

Eram melancólicas, amargas, alegres, esperançosas, heróicas, suas palavras eram humanas... 


\section{Eylül 1945}

Bu geç vakit

bu sonbahar gecesinde

kelimelerinle doluyum;

zaman gibi, madde gibi ebedî,

göz gibi çıplak,

el gibi ağır

ve yıldızlar gibi pırıl pırıl

kelimeler.

Kelimelerin geldiler bana,

yüreğinden, kafandan, etindendiler.

Kelimelerin getirdiler seni,

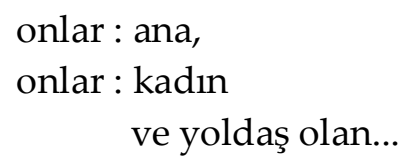

Mahzundular, acıydılar, sevinçli, umutlu, kahramandılar, kelimelerin insandılar... 


\section{1 de setembro de 1945}

O nosso filho está doente,

o pai dele está na prisão,

em suas mãos está a sua cabeça pesada,

a nossa condição reflete a situação do mundo...

As pessoas conduzirão as outras a dias melhores,

o nosso filho melhorará,

o pai dele sairá da prisão,

o fundo dos seus olhos dourados sorrirá,

a nossa condição reflete a situação do mundo...

\section{Eylül 1945}

Oğlumuz hasta,

babası hapiste,

senin yorgun ellerinde ağır başın,

dünyanın hali gibi halimiz...

İnsanlar, daha güzel günlere insanları taşır,

oğlumuz iyileşir,

babası çıkar hapisten,

güler senin altın gözlerinin içi,

dünyanın hali gibi halimiz... 


\section{2 de setembro de 1945}

Quando leio um livro:

nele você está,

quando ouço uma canção:

nela você está.

Quando me assento para comer o meu pão:

sentada diante de mim você está,

quando trabalho:

diante de mim você está.

Você, que está sempre presente comigo:

não podemos conversar,

não podemos ouvir nossas vozes:

você é minha viúva há oito anos... 
Marco Syrayama de Pinto e John Milton. Poemas a Piraye, de Nazım Hikmet

\section{Eylül 1945}

Kitap okurum:

içinde sen varsın,

şarkı dinlerim:

içinde sen.

Oturdum ekmeğimi yerim:

karşımda sen oturursun,

çalışırım:

karşımda sen.

Sen ki, her yerde «hâzırı nâzır»ımsın,

konuşamayız seninle,

duyamayız sesini birbirimizin:

sen benim sekiz yıldır dul karımsın... 


\section{3 de setembro de 1945}

O que ela está fazendo agora mesmo, neste exato momento?

Está em casa, na rua,

está trabalhando, está deitada, está em pé?

Talvez tenha levantado o seu braço,

$-\mathrm{ah}$ !

como o seu pulso branco e grosso fica tão nu com esse movimento!... -

O que ela está fazendo agora mesmo, neste exato momento?

Talvez tenha um gatinho no seu colo, está acariciando-o.

Talvez esteja caminhando, prestes a dar um passo,

- os pés amados que a trazem a mim em todos os meus dias escuros!... -

E em que está pensando

será que em mim?

$\mathrm{Ou}$

sei lá

por que o feijão não se fez ainda?

ou por que a maioria das pessoas está infeliz?

Em que está pensando agora mesmo, neste exato momento? 


\section{Eylül 1945}

O şimdi ne yapıyor

şu anda şimdi, şimdi?

Evde mi, sokakta mi,

çalışıyor mu, uzanmış mi, ayakta mı?

Kolunu kaldırmış olabilir,

- hey gülüm,

beyaz, kalın bileğini nasıl da çırçıplak eder bu

hareketi!...-

O şimdi ne yapıyor,

şu anda, şimdi, şimdi?

Belki dizinde bir kedi yavrusu var,

okşuyor.

Belki de yürüyordur, adımını atmak üzredir,

- her kara günümde onu bana tıpış tıpış getiren

Ve ne düşünüyor

sevgili, canımın içi ayaklar!...-

beni mi?

Yoksa

ne bileyim

fasulyanın neden bir türlü pişmediğini mi?

Yahut, insanların çoğunun

neden böyle bedbaht olduğunu mu?

O şimdi ne düşünüyor,

şu anda, şimdi, şimdi?... 


\section{4 de setembro de 1945}

O mar mais bonito:

é aquele que não foi descoberto ainda.

A criança mais bonita:

não cresceu ainda.

Nossos melhores dias:

são aqueles que não vivemos ainda.

A palavra mais bonita que quero lhe dizer:

é aquela que não disse ainda...

\section{Eylül 1945}

En güzel deniz:

henüz gidilmemiş olanıdır.

En güzel çocuk:

henüz büyümedi.

En güzel günlerimiz:

henüz yaşamadıklarımız.

Ve sana söylemek istediğim en güzel söz:

henüz söylememiş olduğum sözdür... 


\section{5 de setembro de 1945}

São 21 horas.

Tocou o sino na praça,

as portas das celas estão quase fechando.

Desta vez a prisão durou um pouco mais:

oito anos...

Viver: é um negócio cheio de esperança, meu amor,

viver:

é um negócio sério, assim como é amá-la...

\section{Eylül 1945}

Saat 21.

Meydan yerinde kampana vurdu, nerdeyse koğuşların kapıları kapanır.

Bu sefer hapislik uzun sürdü biraz:

8 yil...

Yaşamak: ümitli bir iştir, sevgilim, yaşamak:

seni sevmek gibi ciddî bir iştir... 


\section{6 de setembro de 1945}

Nos escravizaram,

nos aprisionaram:

a mim dentro das paredes,

a você, fora delas.

A nossa condição é insignificante.

O pior é:

conscientemente ou não,

carregar a prisão dentro de si...

A maioria das pessoas está destinada a essa situação,

as pessoas que são honestas, trabalhadoras e boas

e que merecem ser amadas assim como eu a amo...

\section{Eylül 1945}

Bizi esir ettiler,

bizi hapse attılar:

beni duvarların içinde,

seni duvarların dışında.

Ufak iş bizimkisi.

Assl en kötüsü:

bilerek, bilmeyerek

hapisaneyi insanın kendi içinde taşıması...

İnsanların birçoğu bu hale düşürülmüş,

namuslu, çalışkan, iyi insanlar

ve seni sevdiğim kadar sevilmeye lâyık... 


\section{0 de setembro de 1945}

Pensar em você é algo bom

é algo cheio de esperança

é como escutar a canção mais bonita da voz mais linda do mundo.

Mas a esperança não basta mais para mim,

eu não quero mais escutar música

eu quero cantá-la...

\section{Eylül 1945}

Seni düşünmek güzel şey

ümitli şey

dünyanın en güzel sesinden en güzel şarkıyı dinlemek gibi

bir şey.

Fakat artık ümit yetmiyor bana,

ben artık şarkı dinlemek değil

şarkı söylemek istiyorum... 


\section{1 de outubro de 1945}

Acima da montanha:

há uma nuvem carregada do sol da tarde acima da montanha.

Hoje também:

passou sem você, ou seja, passou meio sem vida hoje também.

Logo florirão

bem vermelhinhas:

as belas-da-noite logo florirão bem vermelhinhas.

As asas silenciosas e corajosas carregam pelo ar

a nossa separação que parece um exílio...

\section{Ekim 1945}

Dă̆ın üstünde:

akşam güneşiyle yüklü olan bir bulut var dağın üstünde.

Bugün de:

sensiz, yani yarı yarıya dünyasız geçti bugün de.

Birazdan açar

kırmızı kırmızı:

gecesefaları birazdan açar kırmızı kırmızı.

Taşır havamızda sessiz, cesur kanatlar

vatandan ayrılığa benzeyen ayrılığımızı... 
Marco Syrayama de Pinto e John Milton. Poemas a Piraye, de Nazım Hikmet

\section{2 de outubro de 1945}

Os ventos fluem,

o mesmo galho da cerejeira não balança com o mesmo vento.

Os pássaros gorjeiam na árvore:

as asas querem voar.

A porta está fechada:

precisa ser aberta à força.

Eu preciso de você:

bonita como você,

amigável

e amável seja a vida...

Sei que ainda não acabou

o banquete da miséria...

Mas acabará... 


\section{Ekim 1945}

Rüzgâr akar gider,

aynı kiraz dalı bir kere bile sallanmaz aynı rüzgârla.

Ağaçta kuşlar cıvıldaşır:

kanatlar uçmak ister.

Kapı kapalı:

zorlayıp açmak ister.

Ben seni isterim:

senin gibi güzel,

dost

ve sevgili olsun hayat...

Biliyorum henüz bitmedi

sefaletin ziyafeti...

Bitecek fakat... 
Marco Syrayama de Pinto e John Milton. Poemas a Piraye, de Nazım Hikmet

\section{5 de outubro de 1945}

Ambos sabemos, meu amor,

eles ensinaram:

a ficar com fome, com frio,

o cansaço de morte

e a estar separados.

Ainda não fomos obrigados a matar

e não aconteceu de sermos mortos.

Ambos sabemos, meu amor,

nós podemos ensinar:

a lutar pelo nosso povo

e a amar

a cada dia mais intensamente

um pouco melhor. 


\section{Ekim 1945}

İkimiz de biliyoruz, sevgilim, öğrettiler:

aç kalmayı, üşümeyi, yorgunluğu ölesiye ve birbirimizden ayrı düşmeyi. Henüz öldürmek zorunda bırakılmadık ve öldürülmek işi geçmedi başımızdan.

İkimiz de biliyoruz, sevgilim, ögretebiliriz :

dövüşmeyi insanlarımız için ve her gün biraz daha candan biraz daha iyi sevmeyi... 
Marco Syrayama de Pinto e John Milton. Poemas a Piraye, de Nazım Hikmet

\section{6 de outubro de 1945}

As nuvens estão passando: pesadas, cheias de notícias.

Está ficando amassada na minha mão a carta que não chegou ainda

o coração está na beira dos cílios.

Despede-se da terra que se estende no horizonte.

Sinto vontade de gritar: - "Pi r a y e,

Pir a y e !..."

\section{Ekim 1945}

Bulutlar geçiyor: haberlerle yüklü, ağır.

Buruşuyor hâlâ gelmeyen mektup avucumda.

Yürek kirpiklerin ucunda

uzayıp giden toprak uğurlanır.

Benim bağırasım gelir: - "Pî r â y e, Pîr â y e !..." - diye... 


\section{7 de outubro de 1945}

Atravessaram o mar aberto os gritos dos homens à noite com os ventos.

Passear ainda é perigoso

no mar aberto à noite...

Faz seis anos que este campo não é arado, estão lá os rastros dos tanques como sempre estiveram. Os rastros dos tanques estarão cobertos de neve neste inverno.

Ó luz dos meus olhos, luz dos meus olhos, os noticiários estão mentindo de novo: para que o balanço dos exploradores feche com cem por cento de lucro.

Mas quem voltou do banquete do Anjo da Morte voltou com a sentença... 
Marco Syrayama de Pinto e John Milton. Poemas a Piraye, de Nazım Hikmet

\section{Ekim 1945}

İnsan çığlıkları geçti geceleyin açık denizleri

rüzgâr-

-larla.

Dolaşmak tehlikeli hâlâ

geceleyin açık denizleri...

Altı yıldır sürülmedi bu tarla,

duruyor olduğu gibi tank paletlerinin izleri.

Tank paletlerinin izleri

kapanır bu kış karla.

Ah, gözümün nuru, gözümün nuru,

yine yalan söylüyor antenler:

alın teri tacirleri kapatabilsin diye defteri yüzde yüz kârla.

Fakat Ezrailin sofrasından dönenler

döndüler verilmiş kararlarla... 


\section{8 de outubro de 1945}

Me tornei um homem insuportável de novo:

Sem sono, mal-humorado, maldito.

Um dia,

Trabalho como se estivesse xingando, espancando um animal arisco,

no outro dia

Deitado o dia inteiro,

tenho em minha boca uma canção preguiçosa como um cigarro apagado

E me deixam louco

o ódio e a compaixão que sinto por mim mesmo...

Me tornei um homem insuportável de novo:

Sem sono, mal-humorado, maldito.

Estou sem razão como sempre.

Não tem porquê,

e é impossível haver um.

O que eu faço é vergonhoso,

horrível.

Mas não depende de mim

eu tenho ciúmes de você

me perdoe... 


\section{Ekim 1945}

Çekilmez bir adam oldum yine:

uykusuz, aksi, nâlet.

Bir bakıyorsun ki

ana avrat söver gibi, azgın bir hayvanı döver gibi bugün çalışıyorum,

sonra bir de bakiyorsun ki

ağzımda sönük bir cıgara gibi tembel bir türkü

sabahtan akşama kadar sırtüstü yatıyorum ertesi gün.

Ve beni çileden çıkartıyor büsbütün

kendime karşı duyduğum nefret

ve merhamet...

Çekilmez bir adam oldum yine:

uykusuz, aksi, nâlet.

Yine her seferki gibi haksızım.

Sebep yok,

olması da imkânsız.

$\mathrm{Bu}$ yaptığım iş ayıp

rezalet.

Fakat elimde değil

seni kıskaniyorum

beni affet... 


\section{9 de outubro de 1945}

Sonhei com você ontem à noite:

você estava sentada aos meus pés.

Você levantou sua cabeça e olhou para mim com seus olhos grandes e dourados.

Me perguntou algumas coisas.

Seus lábios molhados se abrem e fecham,

mas não ouço sua voz.

O relógio toca no meio da noite em algum lugar como se trouxesse uma notícia luminosa.

No ar tem um sussurro sem começo e fim.

No meu ouvido tem

a canção do meu canário Memo na sua gaiola vermelha,

o crepitar das sementes brotando numa terra arada

o zumbido de uma multidão certa e vitoriosa.

Seus lábios molhados sempre se abrem e fecham,

mas não ouço sua voz...

Acordei deprimido.

Parece que dormi em cima do livro.

Estou pensando:

será que todas essas vozes eram sua voz? 


\section{Ekim 1945}

Dün gece rüyama girdin:

dizimin dibinde oturuyormuşun.

Başını kaldırdın, kocaman, sarı gözlerini bana çevirdin. Bir şeyler soruyormuşun.

Islak dudakların kapanıp açlıyor, sesini duymuyorum ama.

Gecenin içinde bir yerlerde aydınlık bir haber gibi saat çalıyor.

Havada fısıltısı başsızlığın ve sonsuzluğun.

Kırmızı kafesinde, kanaryamın: «Memo»mun türküsü, sürülmüş bir tarlada toprağı itip yükselen tohumların çitırdisı

ve bir kalabalığın haklı ve muzaffer uğultusu geliyor kulağıma.

Senin ıslak dudakların hep öyle açılıp kapanıyor sesini duymuyorum ama...

Kahrederek uyandım.

Kitabın üstünde uyuyakalmışım meğer.

Düşünüyorum:

yoksa senin miydi bütün o sesler? 


\section{0 de outubro de 1945}

Enquanto olho para seus olhos

o cheiro de um solo ensolarado bate no meu rosto,

me perco num campo de trigo...

Seus olhos são como um precipício verde sem fim,

uma matéria infinita que não pára de mudar:

que explicam seus segredos pouco a pouco cada dia

mas nunca

se entregarão por inteiro...

\section{Ekim 1945}

\section{Gözlerine bakarken}

güneşli bir toprak kokusu vuruyor başıma,

bir buğday tarlasında, ekinlerin içinde kayboluyorum...

Yeşil pırıltılarla uçsuz bucaksız bir uçurum,

durup dinlenmeden değişen ebedî madde gibi gözlerin:

sırrını her gün bir parça veren

fakat hiçbir zaman

büsbütün teslim olmayacak olan... 


\section{8 de outubro de 1945}

Ao sair da porta do castelo para encontrar com a morte, e olhar para trás, para a cidade pela última vez, vamos poder dizer estas palavras, meu amor:

“- Embora você não nos tenha feito feliz, trabalhamos com toda a nossa força

para satisfazê-la.

A sua jornada rumo à felicidade continua,

a vida continua.

Temos a consciência limpa,

no nosso coração há satisfação do seu pão merecido,

nos nossos olhos há a tristeza da separação de sua luz, chegamos e já estamos partindo

seja feliz, cidade de Alepo!" 


\section{Ekim 1945}

Kale kapısından çıkarken ölümle buluşmak üzre, son defa dönüp baktığımızda şehre, sevgilim, şu sözleri söyleyebileceğiz :

«- Pek de öyle güldürmedinse de yüzümüzü, çalıştık gücümüzün yettiği kadar

seni bahtiyar

kılalım diye.

Devam ediyor bahtiyarlığa doğru gidişin, devam ediyor hayat.

İçimiz rahat, gönlümüzde hak edilmiş ekmeğine doymuşluk, gözümüzde ışığından ayrılmanın kederi, işte geldik gidiyoruz şen olasın Halep şehri...» 
Marco Syrayama de Pinto e John Milton. Poemas a Piraye, de Nazım Hikmet

\section{7 de outubro de 1945}

Somos a metade da maçã

a outra é este mundo imenso.

Somos a metade da maçã

a outra é o nosso povo.

Você é uma metade da maçã

eu a outra

nós dois...

\section{Ekim 1945}

Bir elmanın yarısı biz

yarısı bu koskoca dünya.

Bir elmanın yarısı biz

yarısı insanlarımız.

Bir elmanın yarısı sen

yarısı ben

ikimiz... 


\section{8 de outubro de 1945}

Com a fragrância do gerânio-rosa,

o murmúrio do mar,

com suas nuvens cheias e seu solo sábio

Eis o outono...

Meu amor,

A idade chegou.

Me parece que

nós vivemos uma aventura de mil anos.

Mas nós ainda

somos crianças com os olhos arregalados

correndo debaixo do sol de mãos dadas e com os pés descalços...

\section{Ekim 1945}

Itır saksisinda artan koku,

denizlerde uğultular

ve işte dolgun bulutları ve akıllı toprağıyla sonbahar...

Sevgilim,

yaş kemâlini buldu.

Bana öyle gelir ki

belki bin yıllık bir ömrün macerası geçti başımızdan.

Ama biz hâlâ

güneşin altında el ele yalnayak koşan

hayran gözlü çocuklarız... 


\section{5 de novembro de 1945}

Esqueça as amendoeiras floridas.

Não vale a pena,

não deve ser lembrado

o que é impossível de voltar.

Seque seus cabelos molhados no sol:

deixe que as tranças úmidas e vermelhas brilhem com o aroma de frutas maduras...

Meu amor, meu amor,

a estação

é outono...

\section{Kasım 1945}

Çiçekli badem ağaçlarını unut.

Değmez,

bu bahiste

geri gelmesi mümkün olmayan hatırlanmamalı.

Islak saçlarını güneşte kurut :

olgun meyvelerin baygınlığıyla pırıldasın

nemli, ağır kızıltılar...

Sevgilim, sevgilim,

mevsim

sonbahar... 


\section{8 de novembro de 1945}

Chegou a mim sua voz madura e molhada por cima dos tetos da minha cidade distante pelos fundos do mar de Mármara

e passando

pelo solo de outono.

Durou três minutos.

Depois, só a escuridão do telefone desligado...

\section{Kasım 1945}

Uzaktaki şehrimin damları üzerinden ve Marmara denizinin dibinden geçip sonbahar topraklarını aşarak

olgun ve islak geldi sesin.

$\mathrm{Bu}$, üç dakikalık bir zamand.

Sonra, telefon simsiyah kapand1... 


\section{2 de novembro de 1945}

Mornos e sibilantes como o sangue que jorra da veia começaram a soprar os últimos ventos do sul.

Estou escutando o ar:

a pulsação está desacelerando.

Tem neve no topo do Uludağ,

E no planalto de Kirezli estão dormindo confortavelmente os ursos em cima das folhas vermelhas da castanheira.

Os álamos estão se despindo no vale.

Os casulos do bicho-da-seda estão prontos

O outono está prestes a acabar,

A terra vai entrar em um sono profundo logo, logo.

E nós vamos passar mais um inverno:

nos aquecendo com o fogo de nossa esperança sagrada e com nossa grande raiva... 


\section{Kasim 1945}

Damardan boşanan kan gibi llık ve uğultulu

son lodoslar esmeye başladı.

Havayı dinliyorum :

nabız yavaşladı.

Uludağda, zirvede kar

ve Kirezli-yaylada şahane ve şipşirin yatmış uykudadır

kırmızı kestane yapraklarının üstünde ayılar.

Ovada kavaklar soyunuyor.

İpekböceği tohumları kışlaklarına gitti gidecek,

sonbahar bitti bitecek,

nerdeyse girecek gebe-uykularına toprak.

Ve biz yine bir kış daha geçireceğiz :

büyük öfkemizin içinde

ve mukaddes ümidimizin ateşinde isınarak... 


\section{3 de novembro de 1945}

Não tem descrição, - eles dizem, - a pobreza de Istambul, a fome, - eles dizem, - fez o povo sofrer, a tuberculose, - eles dizem, - está em toda parte.

Garotinhas estão sendo... - eles dizem,

Em terrenos baldios e nos assentos dos cinemas... $\cdots \cdots$

.........

Notícias terríveis estão chegando de minha cidade distante: A cidade das pessoas honestas, trabalhadoras, pobres minha Istambul verdadeira,

Esta é a cidade que é o seu habitat, meu amor

e para onde quer que seja exilado, em qualquer prisão em que eu estiver

eu a levo em minha sacola nas costas

como a dor da perda de um filho no meu coração

como sua imagem que levo nos meus olhos... 


\section{Kasim 1945}

Tarif kabul etmez, - diyorlar, - İstanbulun sefaleti, milleti, - diyorlar, - kırıp geçirdi açlık, verem illeti, - diyorlar, - diz boyu.

Şu kadarcık kız çocuklarını, - diyorlar, yangın yerlerinde, sinema localarında... $\ldots \ldots$

Kara haberler geliyor uzaktaki şehrimden :

namuslu, çalışkan, fakir insanların şehri sahici İstanbulum,

sevgilim, senin mekânın olan

ve nereye sürülsem, hangi hapiste yatsam sırtımda, torbamın içinde götürdüğüm ve evlât acısı gibi yüreğimde, senin hayalin gibi gözlerimde taşıdı̆̆ım şehir... 


\section{0 de novembro de 1945}

Embora ainda haja alguns cravos nos vasos

o vale já foi arado faz tempo

e as sementes estão sendo semeadas.

As azeitonas estão sendo colhidas.

Por um lado, o inverno está começando

por outro, estão preparando sulcos para plantar mudas.

Quanto a mim, estou cheio de saudade de você

estou deitado em Bursa como um navio ancorado

cheio de ansiedade para grandes jornadas...

\section{Kasım 1945}

Saksılarda hâlâ tek tük karanfil bulunursa da ovada güz nadasları yapıldı çoktan,

Ve zeytin devşirilmekte.

$$
\text { tohum saçıliyor. }
$$

Bir yandan kışa girilmekte,

bir yandan bahar fidelerine yer açılıyor.

Bense hasretinle dolu

ve büyük yolculukların sabırsızlığıyla yüklü yatıyorum demirli bir şilep gibi Bursada... 


\section{4 de dezembro de 1945}

Tire do baú o vestido que usou quando nos vimos pela primeira vez,

vista-se,

como as árvores na primavera...

Coloque no seu cabelo

o cravo que mandei da prisão dentro de uma carta,

levante sua testa branca e larga cheia de rugas que convidam beijos,

num dia assim, não pode ficar desanimada e triste,

pelo contrário,

num dia assim, tem que estar bonita como uma bandeira de rebelião

a mulher de Nâzým Hikmet...

\section{5 yılı Aralık ayının dördü}

İlk göz göze geldiğimiz günkü elbiseni çıkar sandıktan, giyin, kuşan,

benze bahar ağaçlarına...

Hapisten

mektubun içinde yolladığım karanfili tak

saçlarına,

kaldır, öpülesi çizgilerle kırışık beyaz, geniş alnını, böyle bir günde yılgın ve kederli değil,

ne münasebet,

böyle bir günde bir isyan bayrağı gibi güzel olmalı

Nâzım Hikmetin

kadını... 


\section{5 de dezembro de 1945}

Surgiu uma fenda na estiva.

Os escravos estão destruindo os seus grilhões.

O vento da estrela boreal está soprando,

ele vai jogar este barco em cima das rochas.

Este mundo, este navio pirata vai afundar, inevitavelmente vai afundar.

E vamos construir um mundo

livre, contente e cheio de esperança como a sua fronte, minha Piraye...

\section{Aralik 1945}

Delindi sintine,

esirler parçalamakta pırangaları.

Y1ldız-poyrazdir esen,

tekneyi kayaların üstüne atacak.

Bu dünya, bu korsan gemisi batacaktır, taş çatlasa batacak.

Ve senin alnın gibi hür, ferah ve ümitli bir âlem kuracağız Pirâyem... 


\section{6 de dezembro de 1945}

Eles são inimigos da esperança, meu amor, são inimigos da água corrente, da árvore que está frutificando, da vida que está se desenvolvendo. Porque a morte carimbou a testa deles:

- dentes apodrecendo, carne se deteriorando-, vão ser destruídos e nunca mais voltarão.

E sem dúvida, meu amor, sem dúvida, a liberdade caminhará livremente neste país lindo com a sua melhor roupa:

o uniforme de operário...

\section{Aralık 1945}

Onlar ümidin düşmanıdır, sevgilim, akar suyun,

meyve çağında ağacın,

serpilip gelişen hayatın düşmanı.

Çünkü ölüm vurdu damgasını alınlarına :

- çürüyen diş, dökülen et - ,

bir daha geri dönmemek üzre yıkılıp gidecekler.

Ve elbette ki, sevgilim, elbet, dolaşacaktır elini kolunu sallaya sallaya, dolaşacaktır en şanlı elbisesiyle : işçi tulumuyla bu güzelim memlekette hürriyet... 


\section{7 de dezembro de 1945}

É inimigo do toalheiro Recep em Bursa,

É inimigo do ajustador Hasan em Karabük, da pobre fazendeira dona Hatçe, do camponês Süleyman, é inimigo da pessoa que pensa, esta pátria que é o lar dessas pessoas, meu amor, eles são inimigos da pátria...

\section{Aralık 1945}

Bursada havlucu Recebe, Karabük fabrikasında tesviyeci Hasana düşman, fakir-köylü Hatçe kadına, 1rgat Süleymana düşman, sana düşman, bana düşman, düşünen insana düşman, vatan ki bu insanların evidir, sevgilim, onlar vatana düşman... 


\section{2 de dezembro de 1945}

As árvores brilham com sua última força no vale:

dourado

cobre

bronze e madeira...

Os cascos dos bois afundam suavemente na terra molhada.

E as montanhas cobertas de névoa

cor de chumbo e úmidas...

O outono acabou hoje.

Os gansos selvagens passaram voando rapidamente.

Acho que estão indo para o lago de Iznik.

O ar está fresco,

Tem cheiro de fuligem,

Tem cheiro de neve no ar...

Gostaria de estar fora agora,

cavalgando em direção às montanhas.

"Você não sabe andar a cavalo", você vai dizer.

Mas não ria e não fique com ciúmes de mim,

adquiri um novo hábito na prisão:

de amar a natureza quase tanto quanto a você,

E vocês dois estão longe... 


\section{Aralık 1945}

A ğaçlar ovada son bir gayretle pırıldamakta :

$$
\begin{aligned}
& \text { pul pul altın } \\
& \text { bakır } \\
& \text { tunç ve tahta... }
\end{aligned}
$$

Öküzlerin ayakları yaş toprağa gömülüyor yumuşacık.

Ve dağlar dumana batık

$$
\text { kurşunî, sırılsıklam... }
$$

Tamam,

sonbahar belki bugün bitti artık.

Yaban kazları hızla gelip geçti demin

$$
\text { herhal İznik gölüne gidiyorlar. }
$$

Havada serin

havada is kokusu gibi bir şey :

havada kar kokusu var...

Şimdi dişarda olmak,

dörtnala sürmek dağlara doğru atı.

«- Ata binmesini de bilmezsin,» - - diyeceksin ama

şakayı bırak ve kıskanma,

yeni bir huy edindim hapiste :

seni sevdiğim kadar değilse de

hemen hemen ona yakın seviyorum tabiatı...

Ve ikiniz de uzaktasınız... 


\section{3 de dezembro de 1945}

Começou a nevar de repente à noite.

A manhã começou com os corvos voando por cima dos galhos branquinhos.

Inverno no vale de Bursa, até onde os olhos alcançam:

O sem começo e o sem fim vêm à mente.

Meu amor,

a estação mudou

de repente depois de tantas mudanças.

E embaixo da neve

a vida continua, soberba

e ativa...

\section{Aralık 1945}

Gece kar birdenbire bastırmış.

Bembeyaz dallardan dağılan kargalarla başladı sabah.

Göz alabildiğine Bursa ovasında kış :

başsızlık ve sonsuzluk geliyor akla.

Sevgilim,

değişti mevsim

çekişen gelişmelerden sonra bir sıçramakla.

Ve karın altında mağrur

hamarat

sürüp gidiyor hayat... 


\section{4 de dezembro de 1945}

Droga! O inverno está rigoroso...

Como estão você e minha ilustre Istambul?

Você tem carvão suficiente?

Conseguiu comprar lenha?

Tape as frestas das janelas com folhas de jornal.

Vá para a cama cedo à noite.

Não deve ter nada para vender em casa.

Sentir frio com a barriga não totalmente cheia:

no mundo, no nosso país e cidade

somos a maioria...

\section{Aralık 1945}

Hay aksi lânet, fena bastırdı kış...

Sen ve namuslu İstanbulum ne haldesiniz kim bilir?

Kömürün var mi?

Odun alabildin mi?

Camların kıyısına gazete kâadı yapıştır.

Gece erkenden yatağa gir.

Evde de satılacak bir şey kalmamıştır.

Yarı aç, yarı tok üşümek :

dünyada, memleketimizde ve şehrimizde

bu işte de çoğunluk bizde... 